\title{
Approaching Resilience for Climate Change Adaptation in Complex Milieus: The Case of Vulnerable Neighborhoods in Cartagena de Indias
}

\author{
Mauricio Luna-Galván ${ }^{1}$, Iván Vargas-Chaves², PhD.
}

\begin{abstract}
Tackling related climate change impacts and extreme weather events in urban areas located in developing countries is increasingly becoming a challenge for several stakeholders. Responses to such impacts are being framed and addressed by strategies and policies under the climate change adaptation and mitigation frameworks. However, approaching resilience and adaptive capacities are ever more in need in complex neighborhoods, especially when these are facing climate impacts such as flooding. Framing social dimensions into that adaptive capacity in complex urban systems characterized by poverty, exclusion and the poor public services access makes harder their living standards. Thereby, frameworks taking into account social elements and key indicators of inclusiveness, contribute to the understanding of the social fabrics based on the living conditions of disadvantaged localities.

This special issue explores resilience in the wake of climate-related events such as flooding in neighborhoods with striking social, economic and environmental conditions. Studying the case of the flood-suffering neighborhood of Fredonia in Cartagena, Colombia, will shed light on this particular issue by providing relevant evidence that the levels of climate impacts and hazards occurring in vulnerable urban areas in developing countries, rely on particular social traits that ultimately undermine adaptation efforts for resilience, hence becoming a social problem.
\end{abstract}

Keywords: Climate Change Adaptation; Climate Events; Resilience; Urban Complexities; Urban Inclusiveness; Vulnerable Neighborhoods.

\section{Introduction}

Globally, the impacts of climate-related disasters are increasing, and there may be exacerbated in cities due to interactions of climate and vulnerabilities caused by three drivers: urbanization; the weakness and incapacities of governments; and the development and expansion of cities in high risk-sites (Seto \& Satterthwaite, 2010; Dodman, Bicknell \& Satterthwaite, 2012).

Urban centers concentrate a large proportion of the most at risk from the effects of climate change especially in developing countries in comparison to developed countries (Levy \& Patz, 2015: 315; World Bank, 2014). The impacts have brought in recent years the question of how to evolve more resilient urban communities in hazard-prone areas. Coastal cities such as Cartagena, Colombia, are already exposed to higher precipitation, sea level rise and erosion causing large floods that will likely exacerbate these hazards (Bernstein et al, 2007). Relevant risk factors generally increase impacts, and these are determined by existing social and spatial segregation (Satterthwaite, 2009). 
Populations suffering the effects, are characterized for being in low-income populations at low latitudes, places where important climate-sensitive health outcomes (eg, malnutrition, diarrhea, and malaria) are highly prevalent and where vulnerability to these outcomes is greatest". Impacts further disrupt buildings, transportation, waste management, water supply and drainage systems, electricity, and fuel supplies, thus making urban infrastructure less resilient (Levy \& Patz, 2015: 312-313).

The imperative to reduce urban's residents vulnerability to the many direct and indirect impacts of it, faces multiple challenges as they must cope with serious constraints on their capacity to adapt to them (Dodman, Bicknell \& Satterthwaite, 2012; Satterthwaite, 2010), that is particularly evidenced in complex contexts in developing countries with higher levels of poverty and inequality gaps, and the city of Cartagena, Colombia sheds lights on that specific context (Plan 4C, 2014).

In the name of adaptation "many cities have to adapt to environmental conditions, site characteristics, and natural resources available to be able to function, whereby infrastructure is required to protect some areas and ensuring provision for water"'(Seto \& Satterthwaite, 2010; Dodman, Bicknell \& Satterthwaite, 2012).

However, such adaption process is largely influenced by stakeholders involved with market forces that fail to achieve social equity, and inclusiveness in communities for resilient transformations (Stevenson \& Petrescu, 2016). Turning adaptation into a response of urban planning towards developing social versus physical resilience improving drainage and provision for coping with heavy rainfall in neighborhoods with a lack of social cohesion (Stevenson \& Petrescu, 2016; Seto \& Satterthwaite, 2010).

The understanding our role as humans around dysfunctional and unequal social milieus and organizational actions (Stevenson \& Petrescu, 2016) in urban contexts is key for an effective and comprehensive adaptation (Luna-Galván, Vargas-Chaves \& FrancoGantiva, 2017). Recent studies have begun to explore this relationship, highlighting the need to connect bottom-up neighborhood development initiatives, which means applying an inclusive focus, and it is further treated as human rights issue as ways to promote social justice and avoid creating new problems or exacerbating existing problems for vulnerable populations with low-income living in unsafe or marginal environments (Levy \& Patz, 2015: 313)

The understanding of neighborhood-level resilience and its indicators is still an underdeveloped area of research. The aim is to expand the discourse in this area and present evidence that explores how the understanding of neighborhood resilience can be viewed through social dimension in relation to factors that increase vulnerabilities, which requires a comprehensive understanding of complex social milieus with multiple stressors and determinants to further explore constraints that diminish the adaptive of the urban poor (Romero-Lankao, 2007)

The present paper explores the social conditions of communities and individuals in developing neighborhood resilience by describing vulnerabilities based the inclusive city indicators of the Sustainable Development Goals, and the contextual complexity of neighborhoods in order to approach resilience. 


\section{Trends of Climate Change in Urban Areas: Flooding}

In tropical climate is likely to produce more extreme weather events, such as cyclones or hurricanes, and has increased precipitation and flooding in some areas. Poor and marginalized people who live in flood plains and drought-prone areas are especially vulnerable to extreme weather events and their adverse consequences on health and human rights. The underlying reason they generally lack access to protective and preventive services and lack the socioeconomic resilience to withstand the adverse consequences of these events. Sea level Rise is another impact that will worsen coastal erosion, exacerbate storm surges, inundate low-lying areas, and cause salinization of coastal aquifers (Levy \& Patz, 2015: 315).

Consequently, climate change threatens to worsen existing socioeconomic and health inequalities within and among communities. Among those adverse health consequences are waterborne and foodborne diseases, malnutrition, violence, and mental health problems (Levy \& Patz, 2015).

Focus on reducing the impact of the hazard, by responding rapidly to flooding, both to get the floodwaters away from the flooded settlements and to respond to the flood's impacts upon people's health, living conditions, assets and livelihoods. Framing Resilience and approaching key instruments to build resilience with a robust social component seems to be a perspective to further explore.

\section{Conceptual Framework}

The theoretical discussion of resilience frameworks contributes to identify indicators to assess progress toward practical conceptual framework when tackling climate events. Integrating climate change adaptation into resilience for disaster vulnerability reduction involves adding climate resilience to a city's development vision; understanding the hazards, vulnerabilities, and risks from a different perspective (Reckien et al, 2017) in order to formulate and improve climate adaptation strategies.

The current discourse on sustainable neighborhoods development focuses on green technologies, strategies for smart and efficient use of resources, carbon footprinting and low-carbon development of neighborhoods (Sharifi, 2016).

However, climate change related disasters amplifies vulnerabilities on people in developing countries due to inadequate provision of protection for urban populations, such as provision for drainage that causes flooding, hence requiring rapid responses to get the floodwaters away from informal settlements that also impacts upon people's health, living conditions, assets and livelihoods, making an imperative the focus on the disadvantaged as critical to address vulnerabilities (Satterthwaite, 2009).

Thereby, differential vulnerability emerges among urban residents due to specific social and physical geographies and "driven by four factors: (1) differing levels of physical exposure; (2) urban development processes that have created a range of built-in risks, such access to critical infrastructure and urban services; (3) social characteristics that influence the allocation of resources for adaptation; and (4) access to institutions, and governance. (Reckien et al, 2017). 
Consequently, recent definitions of resilience include elements knowledge, institutional capacity, and financial and technological resources. Low-income populations in a city will tend to have lower adaptive capacity than high-income populations due to low quality housing on safe sites, lack of infrastructure and poor institutions and governance (Seto \& Satterthwaite, 2010)

Policy imperatives for resilience are now driving the need for a robust understanding of how neighborhood resilience interfaces with complex social context in developing countries. The capacity of vulnerable populations living in dangerous locations, such as floodplains, to cope with it and to adapt is influenced largely by the development context, measured basically by assets, this is particularly relevant as it is described as a stock of resources upon which individuals and communities enhance their capacity.

Those resources encompass a set of elements that include financial assets (incomes or access to credit), physical assets (quality of housing, possessions), natural assets (land or rights to ecosystem services), social assets such as family, and human assets (health and skills); bases and knowledge, and community resources (e.g. for coping the quality and inclusiveness of community organizations that provide or manage safety nets and other short and longer term responses); protective infrastructure and public services (Moser, 2006; Moser \& Satterthwaite, 2010; Pelling, 2003; Tyler \& Moench, 2012).

Based on the above, climate hazards typically erode multiple types of assets and further impoverish such groups. profoundly affect human rights and social justice. These consequences threaten civil and political rights and economic, social, and cultural rights, including rights to life, access to safe food and water, health due to high prevalence of climate-related diseases, and security (Levy \& Patz, 2015)

If adaptation to Climate Change are actions aiming to avoid loss of assets and reduce vulnerability of a system to short-term climate shocks for individual or a household to the adverse impacts of extreme climate events (Seto \& Satterthwaite, 2010), resilience's responses should focused on complex context to address risk reduction. 'Resilience' is rooted both in ecology and the other in sustainable livelihoods. The two dimensions of resilience drawn from ecology, namely the ability to bounce back quickly and the ability to withstand disturbance, also have a history in engineering and risk preparedness (Alexander, 2013; Stein et al, 2013), with a relevant emphasis over vulnerability, as communities can do for themselves and how to strengthen their capacities, which is a way to move away from a 'victim' perspective (Schipper \& Langston, 2015)

The IPCC defines resilience as 'the ability of a social or ecological system to absorb disturbances while retaining the same basic structure and ways of functioning, the capacity of self-organization, and the capacity to adapt to stress and change.' (Bernstein et al, 2007). Stockholm Resilience Center defines as 'the capacity to deal with change and continue to develop' (Constas, Frankenberger \& Hoddinott, 2014), as 'a capacity that enables households and communities to maintain a minimum threshold condition when exposed to shocks and stresses'.

In such way, social approach for adaptation is needed in resilience, as focused on the support systems and capacities of human communities and individual to thrive in response to climate events and to promote social justice (Stevenson \& Petrescu, 2016). Support systems to enhance resilience include foremost physical infrastructure and ecosystems, however peripherical neighborhoods lacks those. One key element in the 
resilience framework are agents in urban systems, comprised by individuals and households (Tyler \& Moench, 2012). Resilience depends crucially on the socially differentiated capacities of different groups and individuals. Poverty, gender, ethnicity and age have all been documented as contributing to differential vulnerability of social groups in cities to climate hazards, through features such as the quality of housing, location and access to services or social networks (Moser \& Satterthwaite, 2010; Pelling, 2003; Tyler \& Moench, 2012). Problematic to define in specific context, needs to be characterized in order to elaborate a framework and a specific set of actions in the neighborhood.

Another element of the resilience framework are the Institutions that respond to climate events, such as institutions of property and tenure, of social inclusion or marginalization and of collective action influence the vulnerability of particular social groups (Adger, Arnell \& Tompkins, 2005). Those institutions enable, support, or constrain and inhibit, the capacities of vulnerable urban groups and their engagement in decision making (Tyler \& Moench, 2012).

Aspects of inclusiveness become relevant in resilience framework, those capabilities and capacities of agents and institutions are key to thrive in response to climate change and its impacts (Brown, Kraftl, \& Pickerill, 2012). As vulnerable citizens, we must understand our role as humans in dysfunctional social environments in the planning and action of climate change.

The majority of the urban poor and marginal populations face the greatest risks due to climate change due to the lack power and access to resources, adequate urban services, and functioning infrastructure. Fostering greater equity and justice within climate action increases a city's capacity to respond to climate change and improves human wellbeing, social capital, and related opportunities for sustainable social and economic development (Reckien et al, 2017).

\section{Methods}

Widening research on resilience at the neighborhood level in specific context requires the use of mixed methods to find out new elements of analysis on the theories previously mentioned. A first approximation to the resilient and vulnerability factors in the neighborhood, mixed use of quantitative and qualitative methods, by conducting a survey to the senior students in I.E Fredonia (High School), each student in the sample of 33, provides information about each their household and the neighborhood conditions.

There is a focus on meeting basic needs, the number of people lacking success to the basic needs are higher in recent years, dwellers living in poor housing in very poor quality, overcrowded housing lacking basic infrastructure and services, inadequate provision for infrastructure in water, sewage, sanitation and drainage. An indication of the scale of urban problems is the number of people living in informal and illegal settlements unable to buy or build (Satterthwaite, 2009).

That explains how worsening housing, income and health, and deficiencies in basic infrastructure. Such problems lead to rethink the way we address the vulnerability of urban populations to climate change responses to it in an articulated fashion as 
processes. Each locality, what is needed is a coherent, integrated response to all environmental hazards and risks. Urban poor should be seen as critical part of the urban system (Dodman, Bicknell \& Satterthwaite, 2012).

Based on the above, the instrument used was designed by taking the adequate and pertinent elements provided by the SDG's goal 11 for inclusive urban centers.

\section{Characterizing the Vulnerabilitities of Fredonia Neighborhood}

Cartagena de Indias, due to its geographical location and its socioeconomic characteristics, is a city vulnerable to climate change. Its population, economic activities and its environment have suffered the consequences of the effects of extreme weather events in recent years (INVEMAR, 2012)

The mangroves of the 'Cienaga de la Virgen have been considerably pressured by the urban sprawl that has occurred on the southeastern side of the Ciénaga de la Virgen, which is a large swamp with an important ecosystem in the city. The surrounding populated areas are facing environmental challes due to the illegal expansion, where landfills and mangrove felling were made for housing construction. Likewise, as these homes have no service infrastructure, the dump from their waste goes directly into the swamp, a situation that greatly affected and affects the mangroves (EPA, 2009; INVEMAR, 2012).

The neighborhood of Fredonia is characterized as vulnerable as it is one of neighborhoods with close proximity to la Ciénaga de la Virgen which is highly impacted by floods, rainfall, and would be affected by sea level rise, as well as an increase in dengue. These neighborhoods are sensitive due to their poverty conditions and poor sewerage coverage. In this sector, the use of residential land predominates and coincides with the area of greatest population expansion in the city (INVEMAR, 2012).

Further inquiry on Climate change related issues in the neighborhoods, have been asking about the climate events Cartagena is more likely to face, respondents are aware that impacts will be floods $38 \%$, and hurricanes $24 \%$. Moreover, $37 \%$ of the population held that health problems are associated with environmental factors such as water, air and noise (Cartagena Cómo Vamos, 2017)

\section{Survey Results}

Based on the instruments applied on the sample of households in Fredonia Neighborhood, the surveys yield the following:

\begin{tabular}{|l|l|l|l|}
\hline Table 1: Questions based on indicators of the SDG goal 11 & Yes & No & NR \\
\hline 1. Household with access to basic public services & $67 \%$ & $33 \%$ & \\
\hline 2. Do you feel safe in the neighborhood & $9 \%$ & $91 \%$ & \\
\hline $3 . \quad$ House with property rights & $91 \%$ & $9 \%$ & \\
\hline $\begin{array}{l}\text { 4. Dos the house has the protection conditions to face } \\
\text { extreme climate and environmental hazards }\end{array}$ & $70 \%$ & $26 \%$ & $3 \%$ \\
\hline $5 . \quad$ Is there an easy access to public transport & $48 \%$ & $52 \%$ & - \\
\hline $6 . \quad$ Is there a service of solid-waste collection in your area? & $76 \%$ & $24 \%$ & - \\
\hline
\end{tabular}




\begin{tabular}{|ll|l|l|l|}
\hline 7. & Is it close the health services (hospital, clinic) & $88 \%$ & $12 \%$ & - \\
\hline 8. & Are you covered by a government subsidy/health? & $76 \%$ & $24 \%$ & -- \\
\hline $9 . \quad$ Regular Water supply & $100 \%$ & $0 \%$ & - \\
\hline $\begin{array}{l}\text { 10. Access to public transport within 500 mts distance and } \\
\text { less than } 20 \mathrm{~min}\end{array}$ & $79 \%$ & $21 \%$ & - \\
\hline $11 . \quad$ Participation in community spaces for decision making & $40 \%$ & $60 \%$ & - \\
\hline $12 . \quad$ Use of gas to cook at the house & $100 \%$ & $0 \%$ & \\
\hline
\end{tabular}

Despite having access to several basic public services, levels of satisfaction are lower. The service of solid-waste collection has a $58 \%$ of satisfaction while $30 \%$ are unsatisfied and $9 \%$ very unsatisfied. Health services marks a $48 \%$ of satisfaction, while $39 \%$ affirm they are unsatisfied and $9 \%$ are very unsatisfied. Furthermore, and based on observation, the neighborhood is difficult to access, about $700 \mathrm{mts}$ from the major road where almost and the police station.

In terms of security, the respondents convey the issue as highly critical as shown on the graphic below.

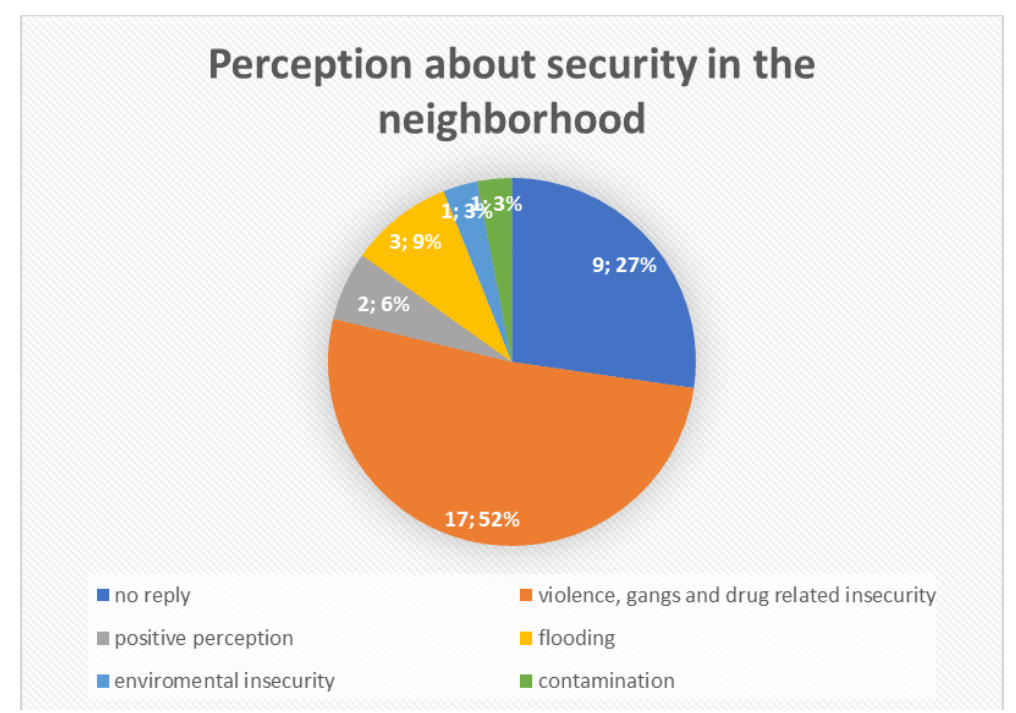

Graphic 1. Perceptions of security in the neighborhood.

\section{Analyzing resilience approximation in the neighborhood}

Adaption require strengthening the social dimension when tackling neighborhood resilience strategies. The living conditions of the agents in the urban systems are critical for change and developing a resilient neighborhoods when addressing climate change as a more comprehensive strategy (Stevenson \& Petrescu, 2016). The case of Fredonia neighborhoods provides revealing evidences on what should be fore steps to address climate change adaptation and to further build the capacities of social agents to keep their assets to housing, their access to health services, ecosystem services 
and treatment of solid waste that cause contamination issues, and ultimately safer places within the urban system to reduce vulnerabilities

The goal 11 of the SDG's provided the components for a first approach to resilience when framing the case within the developing world specific social and environmental context. It demonstrated how ill-functioning institutions, undermines decision-making process to tackle climate challenges, and also showed vulnerabilities in the neighborhoods with low access to institutions, clientelist and social exclusive communities, patriarchal households and patrimonial and/ or marketized states (RamosMejía, Franco-Garcia \& Jauregui-Becker, 2018)

Perceptions on security provided new categories thus highlights and redefine security perceptions in their neighborhood such as those related with the contamination in the area. Despite higher levels in home ownership, access to health, water and gas public services, inhabitants in the neighborhoods are not satisfied with the quality of many of the services, and the security environment, clearly explained by the patterns of poverty, the contamination and the insecurity, conditions that ultimately undermine their assets to address extreme climate events.

\section{Conclusion}

Social conditions and characteristics with lower inclusiveness in complex urban environments in developing countries surge as an evidence that is systematically overlooked, in order to include social vulnerabilities and inclusive elements in resilience for sustainable adaptation strategies (Ramos-Mejía, Franco-Garcia \& Jauregui-Becker, 2018). Reviewing the concepts and practices can help readdress adaption to climate change beyond mainstream and economy-driven policies and strategies, aiming to bring up a more contextualized neighborhood resilience where social structural conditions lie at the core.

Further elements for resilience must allow the creation of spaces to strengthen institutions, shared knowledge and learning processes at community level as important for establishing neighborhood resilience in vulnerable areas are highly recommended.

In addition, different adaptation measures will have to include human rights elements. Framing resilience into human rights perspective brings a new element as access to public services and to re-address security in those neighborhoods other than the traditional ones, thus adding up human security by including the right to security and the right to a standard of living adequate for health and well-being, including housing, medical care, and necessary social services (Levy \& Patz, 2015: 311)

The above results particularly important, as further impacts have being shown the association between climate variables and violent conflict (as well as sociopolitical instability) found that when temperature is high and there is extreme precipitation, there are increases in both sociopolitical instability and the frequency of collective violence in complex urban conditions.

Climate change interacts with other ongoing change processes, knowledge and shared understanding will evolve over time, by including agents, institutions and urban system analysis (Tyler \& Moench, 2012), and to further identifying critical elements that makes them vulnerable and frame it in to a more pertinent, contextualized social and ecological 
approach, that need to be further explored and not focusing efforts only on infrastructure engineering and cost-benefit approaches (Levy \& Patz, 2015: 318).

\section{References}

Adger, W. N., Arnell, N. W., \& Tompkins, E. L. (2005). Successful adaptation to climate change across scales. Global environmental change, 15(2), 77-86.

Alexander, D. E. (2013). Resilience and disaster risk reduction: an etymological journey. Natural Hazards and Earth System Sciences, 13(11), 2707-2716.

Bernstein, L., Bosch, P., Canziani, O., Chen, Z., Christ, R., Davidson, O., ... \& Kundzewicz, Z. (2007). IPCC, 2007: climate change 2007: synthesis report. Contribution of working groups I. II and III to the Fourth Assessment Report of the Intergovernmental Panel on Climate Change. Intergovernmental Panel on Climate Change, Geneva.Retrieved from: http://www. ipcc. ch/ipccreports/ar4-syr. htm.

Brown, G., Kraftl, P., Pickerill, J., \& Upton, C. (2012). Holding the future together: towards a theorisation of the spaces and times of transition. Environment and Planning A, 44(7), 1607-1623.

Cartagena Cómo Vamos (2017). Resultados de la Encuesta de Percepción Ciudadana 2017. Retrieved from: http://www.cartagenacomovamos.org/nuevo/wp-content/uploads/2018/02/Encuesta-dePercepci $\%$ C3\%B3n-Ciudadana-2017-Versi $\%$ C3\%B3n-Web.pdf

Constas, M., Frankenberger, T., \& Hoddinott, J. (2014). Resilience measurement principles: Toward an agenda for measurement design. Food Security Information Network, Resilience Measurement Technical Working Group, Technical Series, 1.

Dodman, D., Bicknell, J., \& Satterthwaite, D. (2012). Adapting cities to climate change: understanding and addressing the development challenges. New York: Routledge.

INVEMAR (2012). Lineamientos para la adaptación al cambio climático de Cartagena de Indias. Proyecto Integración de la Adaptación al Cambio Climático en la Planificación Territorial y Gestión Sectorial de Cartagena de Indias. Cartagena de Indias: INVEMAR. Retrieved from: https://cdkn.org/wp-content/uploads/2012/08/Lineamientos-de-Adaptaci\%C3\%B3n-al-CCCartagena.pdf

Levy, B., \& Patz, J. (2015). Climate change and public health. Oxford: Oxford University Press.

Lindberg, E. (2017). Understanding Climate Change as a Social Issue: How Research Can Help. University of Southern California Repository. Retrieved from: https://dworakpeck.usc.edu/news/understanding-climate-change-social-issue-how-research-canhelp

Luna-Galván, M., Vargas-Chaves, I., \& Franco-Gantiva, A. (2017). Towards an Inclusive Approach for Climate Change Adaptation Strategies: The Case of the Plan 4C in the City of Cartagena de Indias. European Journal of Sustainable Development, 6(3), 457-472.

Moser, C. (2006). Talk of the city: engaging urbanites on climate change. Environmental Research Letters, $1(1), 014006$.

Moser, C., \& Satterthwaite, D. (2010). Toward pro-poor adaptation to climate change in the urban centers of low-and middle-income countries. In R. Mearns \& A. Norton (Eds) Social dimensions of climate change: Equity and vulnerability in a warming world (pp. 231-258). Washington: The World Bank.

Pelling, M. (2003). The Vulnerability of Cities: social resilience and natural disaster. London: Earthscan.

Plan 4C (2014). Plan 4C: Cartagena de Indias Competitiva y Compatible con el Clima. Santa Marta: INVEMAR. Retrieved from: www.invemar.org.co/redcostera1/invemar/docs/12000063_Plan_4C_web.pdf

Ramos-Mejía, M., Franco-Garcia, M. L., \& Jauregui-Becker, J. M. (2018). Sustainability transitions in the developing world: Challenges of socio-technical transformations unfolding in contexts of poverty. Environmental Science \& Policy, 84, 217-223.

Reckien, D., Lwasa, S., Satterthwaite, D., McEvoy, D., Creutzig, F., Montgomery, M. \& Khan, I. (2017). Equity, environmental justice, and urban climate change. Climate Change and Cities: Second Assessment Report of the Urban Climate Change Research Network.

Romero-Lankao, P. (2007) ¿Are we missing the point? Particularities of urbanization, sustainability and carbon emissions in Latin America cities', Environment and Urbanization, 19, 157-175. 
Satterthwaite, D. (2009). The implications of population growth and urbanization for climate change. Environment and Urbanization 21(2): 545-567

Satterthwaite, D. (2010). The role of cities in sustainable development. Sustainable Development Insights, 4, $1-8$.

Seto, K. C., \& Satterthwaite, D. (2010). Interactions between urbanization and global environmental change. Current Opinion in Environmental Sustainability 2(3):127-128

Schipper, E. L. F., \& Langston, L. (2015). A comparative overview of resilience measurement frameworks. ODI Working Paper, 422, 1-30.

Sharifi, A. (2016). From Garden City to Eco-urbanism: The quest for sustainable neighborhood development. Sustainable Cities and Society, 20, 1-16.

Stein, B. A., Staudt, A., Cross, M. S., Dubois, N. S., Enquist, C., Griffis, R., ... \& Pairis, A. (2013). Preparing for and managing change: climate adaptation for biodiversity and ecosystems. Frontiers in Ecology and the Environment, 11(9), 502-510.

Stevenson, F., \& Petrescu, D. (2016) Co-producing neighbourhood resilience. Building Research \& Information 44(7), 695-702.

Tyler, S., \& Moench, M. (2012). A framework for urban climate resilience. Climate and development, 4(4), 311-326.

World Bank (2014). Climate change affects the poorest in developing countries. World Bank News, March 3. Retrieved from: http://www.worldbank.org/en/news/feature/2014/03/03/climate-changeaffectspoorest-developing-countries 